\title{
The sooner the better? Early strategies of peripheral vascular intervention for patients with acute aortic dissection complicated by organ malperfusion
}

\author{
Yutaka Okita, MD
}

\footnotetext{
From the Divisions of Cardiovascular Surgery and Cardiovascular and Pediatric Surgery, Department of Surgery, Kobe University, Kobe, Japan

Disclosures: Author has nothing to disclose with regard to commercial support.

Received for publication Feb 24, 2018; revisions received March 8, 2018; accepted for publication April 2, 2018; available ahead of print June 9, 2018

Address for reprints: Yutaka Okita, MD, Department of Surgery, Kobe University, 7-5-2 Kusunoki-cho, Chuo-ku, Kobe, Japan 650-0017 (E-mail: yokita@med.kobe-u.ac.jp).

J Thorac Cardiovasc Surg 2018;156:490-1

$0022-5223 / \$ 36.00$

Copyright (c) 2018 by The American Association for Thoracic Surgery https://doi.org/10.1016/j.jtcvs.2018.04.015
}

In Japan, 30-day mortality of surgery for acute type A aortic dissection in 2014 was $8.8 \%$. ${ }^{1}$ Some reasons for this higher mortality might be because of the increased recruiting of patients with aortic branch vessel occlusion, resulting in stroke, paraplegia, or renal, mesenteric, or leg ischemia. In this issue of The Journal of Thoracic and Cardiovascular Surgery, Uchida and colleagues have raised many important questions in treating patients with acute aortic dissection (AAD) complicated by organ malperfusion. ${ }^{2}$

The incidence of malperfusion in $\mathrm{AAD}$ has been reported as $4.5 \%$ to $7.7 \%$ in the coronary arteries, $2.6 \%$ to $28.0 \%$ in the carotid arteries, $2.3 \%$ to $13.7 \%$ in the mesenteric arteries, $2.6 \%$ to $12.4 \%$ in the renal arteries, $1.6 \%$ to $12.4 \%$ in the spinal cord, and $6.8 \%$ to $26.1 \%$ in the iliofemoral arteries. ${ }^{3,4}$ The International Registry of Acute Aortic Dissection (IRAD) study showed higher mortality with increased involvement of the aortic branches. The German Registry for Acute Aortic Dissection Type A (GERAADA) study of 2137 patients showed that the allcause 30 -day mortality was $16.9 \%$ and varied substantially according to the number of organ systems affected by malperfusion. ${ }^{5}$

The treatment of patients with acute type A aortic dissection complicated with organ malperfusion has been of controversy. The authors ${ }^{2}$ discuss an alternative treatment of early revascularization in 108 patients with acute type A aortic dissection and malperfusion over a 10 -year period. Thirty-three of 108 patients who underwent early revascularization of malperfused organs before central aortic surgery appeared to fare better than those who did not.

Kawahito et $\mathrm{al}^{6}$ reported that 12 of 196 consecutive patients $(6.1 \%)$ with acute type A aortic dissection suffered myocardial ischemia associated with the dissection. All patients underwent coronary artery bypass grafting accompanied by aortic repair. The reported mortality rate was higher

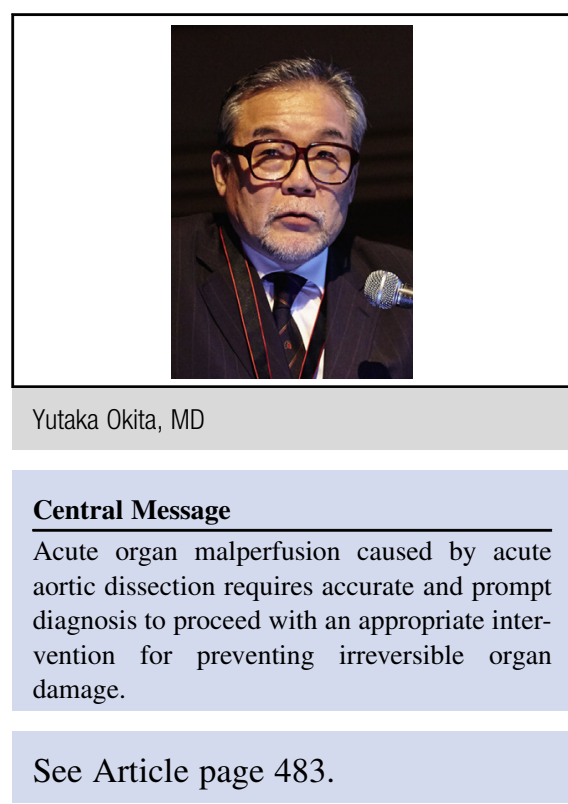

than in patients without coronary malperfusion $(33.3 \%$ vs $8.2 \% ; P=.019)$. Uchida et al concluded that early revascularization with coronary stent placement was effective in preventing postoperative low cardiac output syndrome. ${ }^{2}$

Syncope in patients with dissection might not necessarily represent brain infarction and might be caused by cardiac tamponade or hypotension. Patients are sometimes excluded from definitive surgery or early interventions because of their high mortality and cerebral morbidity. The IRAD study ${ }^{7}$ revealed that aortic repair was not performed in $11 \%$ of non-brain-injured patients, $24.1 \%$ with a cerebrovascular accident, or $33.3 \%$ with coma, echoing a preference to avoid surgery in high-risk patients. Eusanio et al reported that hospital mortality was $40.2 \%$ with a cerebrovascular accident and $63.0 \%$ with coma. ${ }^{8}$ The GERAADA study showed neurological dysfunction occurring in $20.3 \%$ of patients with acute type A aortic dissection before surgery, $12.6 \%$ of which resolved postoperatively and $7.7 \%$ persisted. ${ }^{9}$ Urbanski and Wagner ${ }^{10}$ first reported on 2 cases of AAD with bilateral dissection of the common carotid artery, which resulted in cerebral malperfusion. Luehr et $\mathrm{al}^{11}$ performed extra-anatomic aorto-carotid bypass in 23 patients suffering from cerebral malperfusion secondary to aortic dissection. They reported that new stroke was found in $34.8 \%$ and hospital mortality was $13.0 \%$. We believe that aggressive direct reperfusion of 
the carotid artery before aortic repair might reduce neurological complications in patients with brain malperfusion. ${ }^{12}$

Despite successful aortic repair, death often resulted as a result of mesenteric infarction. Fann et $\mathrm{al}^{13}$ suggested that, when indicated, an early aggressive surgical approach focusing primarily on the thoracic aorta, followed by secondary aortic fenestration, superior mesenteric artery revascularization, and/or bowel resection is the most prudent option for treating patients with acute mesenteric ischemia. Cambria et $\mathrm{al}^{4}$ advocated for local surgical treatment of visceral ischemia followed by medical or surgical management of the thoracic aorta. Di Eusanio et al ${ }^{14}$ stated that surgical or hybrid therapy appears to be associated with better long-term outcomes in this setting. Uchida and colleagues ${ }^{2}$ proposed the simple solution of inserting a small catheter into the mesenteric artery, perfusing it, and proceeding to the central repair. Extensive exploration of visceral perfusion should be mandatory, and thoracic aortic repair or direct bypass to the mesenteric artery should be performed when indicated. In conclusion, acute organ malperfusion caused by AAD requires accurate and prompt diagnosis to proceed with an appropriate intervention for preventing irreversible organ damage secondary to ischemia.

\section{References}

1. Masuda M, Okumura M, Doki Y, Endo S, Hirata Y, Kobayashi J, et al; Committee for Scientific Affairs, The Japanese Association for Thoracic Surgery. Thoracic and cardiovascular surgery in Japan during 2014: annual report by The Japanese Association for Thoracic Surgery. Gen Thorac Cardiovasc Surg. 2016;64: 665-97.

2. Uchida K, Karube N, Kasama K, Minami T, Yasuda S, Goda M, et al. Early reperfusion strategy improves the outcomes of surgery for type A acute aortic dissection with malperfusion. J Thorac Cardiovasc Surg. 2018;156:483-9.
3. Hirst AE Jr, Johns VJ Jr, Kime SW Jr. Dissecting aneurysm of the aorta: a review of 505 cases. Medicine. 1958:37:217-79.

4. Cambria RP, Brewster DC, Gertler J, Moncure AC, Gusberg R, Tilson MD, et al. Vascular complications associated with spontaneous aortic dissection. J Vasc Surg. 1988;7:199-209.

5. Czerny M, Schoenhoff F, Etz C, Englberger L, Khaladj N, Zierer A, et al. The impact of pre-operative malperfusion on outcome in acute type A aortic dissection: results from the GERAADA registry. J Am Coll Cardiol. 2015;65:2628-35.

6. Kawahito K, Adachi H, Murata S, Yamaguchi A, Ino T. Coronary malperfusion due to type A aortic dissection: mechanism and surgical management. Ann Thorac Surg. 2003;76:1471-6; discussion 1476.

7. Bossone E, Rampoldi V, Nienaber CA, Trimarchi S, Ballotta A, Cooper JV, et al. Usefulness of pulse deficit to predict in-hospital complications and mortality in patients with acute type A aortic dissection. Am J Cardiol. 2002;89:851-5.

8. Di Eusanio M, Patel HJ, Nienaber CA, Montgomery DM, Korach A, Sundt TM, et al. Patients with type A acute aortic dissection presenting with major brain injury: should we operate on them? J Thorac Cardiovasc Surg. 2013;145: 213-21.e1.

9. Conzelmann LO, Hoffmann I, Blettner M, Kallenbach K, Karck M, Dapunt O, et al. Analysis of risk factors for neurological dysfunction in patients with acute aortic dissection type A: data from the German registry for acute aortic dissection type A (GERAADA). Eur J Cardiothorac Surg. 2012;42:557-65.

10. Urbanski PP, Wagner M. Perfusion and repair technique in acute aortic dissection with cerebral malperfusion and damage of the innominate artery. J Thorac Cardiovasc Surg. 2012;144:982-4.

11. Luehr M, Etz CD, Nozdrzykowski M, Lehmkuhl L, Misfeld M, Bakhtiary F, et al Extra-anatomic revascularization for preoperative cerebral malperfusion due to distal carotid artery occlusion in acute type A aortic dissection. Eur J Cardiothorac Surg. 2016;49:652-8; discussion 658-9.

12. Okita Y, Ikeno Y, Yokawa K, Koda Y, Henmi S, Gotake Y, et al. Direct perfusion of the carotid artery in patients with brain malperfusion secondary to acute aortic dissection. Gen Thorac Cardiovasc Surg. December 28, 2017 [Epub ahead of print].

13. Fann JI, Sarris GE, Mitchell RS, Shumway NE, Stinson EB, Oyer PE, et al. Treatment of patients with aortic dissection presenting with peripheral vascular complications. Ann Surg. 1990;212:705-13.

14. Di Eusanio M, Trimarchi S, Patel HJ, Hutchison S, Suzuki T, Peterson MD, et al Clinical presentation, management, and short-term outcome of patients with type A acute dissection complicated by mesenteric malperfusion: observations from the international registry of acute aortic dissection. J Thorac Cardiovasc Surg. 2013;145:385-90.e1. 